\title{
FEMALE SPORT PARTICIPATION IN SOUTH AFRICAN RURAL SCHOOLS: ANALYSIS OF SOCIO-CULTURAL CONSTRAINTS
}

\author{
Ntwanano Alliance KUBAYI \\ Department of Sport. Rehabilitation and Dental Sciences, Tshwane University of Technology, Private Bag X680, \\ Pretoria, 0001, South Africa \\ (C) 2015 Ntwanano Alliance Kubayi \\ This is an open access article distributed under the Creative Commons Attribution-NonCommercial-NoDerivs license \\ (http://creativecommons.org/licenses/by-nc-nd/3.0/) \\ DOI: $10.1515 /$ eras-2015-0001
}

\begin{abstract}
This study was carried out to examine constraints to sport participation among female secondary school students in Hlanganani rural area, Limpopo Province, South Africa. A total of 101 female students aged 17-24 years from four secondary schools were recruited to participate in the study. A self-administered questionnaire was used to collect data. Results indicated that the dress code, lack of energy, lack of family support and family commitment were identified as major constraints to sport participation among female students. The results of this study provide practical implications for promoting and developing female sports programmes in rural schools. This study suggests that stakeholders such as parents, peers, and teachers should motivate and encourage female students to participate in school sport. Additionally, the study recommended that in order to promote sport participation in rural areas, the values, norms, beliefs, attitudes and customs that restrict females from participating in sport and physical activity should be dissented.
\end{abstract}

Keywords: female, students, sport, participation, constraints

\section{Introduction}

Sport provides young females with self-esteem thereby enhancing experiences by equipping them with skills and knowledge that are necessary to organise and manage their lives in a responsible manner (van Deventer, 1998). Furthermore, participation in sport provides students with the opportunity to socialise with their peers, promotes students' health, improves physical fitness, increases academic performance and improves their sense of relaxation (Malan \& van Deventer, 2013; Ongong'a, Okwara \& Okello, 2010; van Hout, Young, Bassett \& Hooft, 2013). In spite of these benefits, sport participation peaks between the ages of 10 and 13 years, and then consistently declines till the age of 18 years (Ewing \& Seefeldt, 1989). Research has shown that participation in sport is influenced by several constraints which according to Crawford and Godbey (1987) are classified as structural, intrapersonal, and interpersonal constraints. Structural constraints refer to factors such as lack of facilities, time constraints, financial resources, etc. Intrapersonal constraints refer to the psychological states of individuals. Interpersonal constraints are those constraints such as lack of partners or friends. A model proposed by Crawford, Jackson and Godbey (1991) suggests that intrapersonal constraints are encountered first and are then followed by interpersonal and structural constraints.

Another study conducted by Amusa, Toriola, Onyewadume and Dhaliwal (2008), reported aptitude (personal, physical skills, knowledge, body image, illness and fitness), social-cultural (societal norms, values of the sport, customs, beliefs and peer pressure), community awareness (awareness of sport facilities, knowledge of sport facilities and use of sport facilities), socioeconomic (time, finance, equipment and cost of public transport) and environmental constraints (access to facilities, proximity to facilities, motivation, safety and weather conditions) as other major constraints to sport participation. Research has shown that females are more affected by the socio-cultural factors because of their gender roles (Abbasi, 2014). 
Several studies have been carried out to assess constraints to sport participation among secondary school students in townships and urban areas in South Africa. They include studies conducted by Mchunu and Le Roux (2010), Kubayi, Toriola and Monyeki, (2013), and Pule, Kubayi, Toriola and Amusa (2013). These studies indicated that participation in school sports is mainly influenced by factors such as time constraint, lack of parental support, conflict from other interests, lack of sport facilities and equipment, restricted sport programmes and unqualified sport coaches. However, none of these studies were carried out in rural areas. The few available studies undertaken in rural areas include those by Kubayi, Goon, Coopoo and Amusa (2013), which reported that male students participate in sport more than female students. However, the constraints that deterred female students' from sport participation were not assessed in these studies. Therefore, the present study attempts to extend Kubayi et al.'s (2013) study by examining the constraints to sport participation among female students in Hlanganani rural area of Limpopo in South Africa.

\section{Methodology}

\subsection{Sample}

A total of 101 female students aged 17 to 24 years attending four high schools in Hlanganani rural area, Limpopo province of South Africa, volunteered to participate in this study. This age group was chosen because students in this age group, in particular Tsonga people, have the ability to write and read English. Therefore it was feasible for them to fill in the questionnaires without any difficulties. A convenient sampling method was used to recruit the participants to participate in the study. A convenient sampling method was chosen because it is the best way of getting some basic information quickly and efficiently (Sekeran, 2003).

\subsection{Research instrument}

A self-administered questionnaire was used to collect data. The instrument comprised two sections. Section A comprised questions which sought information on the participants' demographic profile. Section B elicited 10 closed ended items which were scored on a 7-point Likert scale ranging from 1(Strongly disagree) to 7 (Strongly agree). The questionnaire was designed based on interviews conducted with female students in schools. A Cronbach alpha coefficient of 0.578 was obtained for this study. Although the alpha value of the questionnaire fell below the benchmark of 0.7 recommended by Nunally (1978); however, according to Kim and Kim (1995), a coefficient of 0.5 to 0.6 is sufficient to conclude the extracted dimensions as reliable.

\subsection{Ethical consideration and procedure}

Prior to data collection, the permission to conduct the study was granted by the Department of Education at Vhembe district, Thohoyandou and Hlanganani circuit office, at Hlanganani rural area, Limpopo Province. Data collection was undertaken by the principal researcher. The principal researcher met with the students, explained the purpose of the study and outlined the data collection procedure to them. Signed informed consents were obtained from all students who participated in the study and they were informed that their participation was voluntary and were assured of anonymity and confidentiality of their responses. To avoid disruption of school lessons, data was collected after school hours. Participants were guided to fill in the questionnaires independently which took them approximately 5 minutes to complete.

\subsection{Statistical analysis}

Statistical analyses were performed using the Statistical Package for Social Sciences (SPSS - Version 21). Descriptive statistics (means and standard deviations) were used to analyse the data. 


\section{Results}

Of the 180 questionnaires that were distributed, 101 questionnaires were returned representing a questionnaire return rate of $56 \%$. A low response rate among students in this study could be supported by the words of Couper (2000) who stated that "not all people included in the sample are willing or able to complete the survey" (p. 473). However, according to Babbie (1990), a 50\% response rate is adequate. Table 1 summarises the constraints on sport participation encountered by female students in rural areas.

Table 1. Constraints to sport participation among female students

\begin{tabular}{lccc}
\hline Constraints & Rank & Mean & Standard deviation \\
\hline Lack of time & 10 & 2.42 & 1.85 \\
Lack of sport facilities & 8 & 3.09 & 2.15 \\
Family commitments & 4 & 3.79 & 2.28 \\
Lack of motivation & 9 & 2.89 & 2.29 \\
No interest & 6 & 3.22 & 2.24 \\
Lack of energy & 2 & 4.35 & 2.16 \\
Lack of family support & 3 & 3.81 & 2.28 \\
I don't like the dress code & 1 & 4.36 & 2.45 \\
Sport is not important & 7 & 3.11 & 2.29 \\
Not in my culture & 5 & 3.70 & 2.43 \\
\hline
\end{tabular}

The five most likely barriers to sport participation perceived by the female students were, "I don't like the dress code" $(\mathrm{M}=4.36)$, "lack of energy" $(\mathrm{M}=4.35)$, "lack of family support" $(\mathrm{M}=$ 3.81), "family commitments" $(M=3.79)$, "not in my culture" $(M=3.70)$, whereas the least barriers were, "No interest" $(\mathrm{M}=3.22)$, "sport is not important" $(\mathrm{M}=3.11)$, "lack of sport facilities" $(\mathrm{M}=3.09)$, "lack of motivation" $(\mathrm{M}=2.89)$ and "lack of time" $(\mathrm{M}=2.42)$.

\section{Discussion}

The purpose of this study was to examine constraints to sport participation among female high school students in Hlanganani rural area of Limpopo Province, South Africa. This study found that "dress code" was a major constraint to sport participation among girls in rural areas. Consistent with a previous study conducted by Walter and Du Randt (2011) among Xhosa women, there is also a perception among Tsonga women that wearing sport attire such as trousers or shorts is not acceptable in their culture. This finding also corroborates those of previous studies undertaken in other African countries. For example, in Egypt, Walseth and Fasting (2003) found that women wearing the krimar (which covers hair and chest) or nikab (also the face) found it more difficult to play sport compared to those wearing the hijab (which covers hair only). A recent study conducted by Frantz and Ngambare (2013) in Rwanda, found that women in the Rwandan culture who are mothers, are obliged to wear special dresses which cover their body. Therefore, this study suggests that policy makers should accommodate female students where their cultures restrict them from participating in sport due to dress code. This could be achieved by letting them participate in sport with long skirts with their heads also covered. The present finding in which female students reported lack of energy as a major barrier to sport participation is consistent with those of a previous study (Allison, Dwyer \& Makin, 1999). Lack of energy may be attributed to the reduction of physical activity participation in physical education/life orientation lessons in schools. In an attempt to motivate female students to participate in sport, teachers and sport coaches should therefore incorporate strategies that promote fun, and enjoyment, which allow students to interact with others. Furthermore, lack of family support was also perceived as a major barrier to sport participation. A similar finding has been reported by Pule, Kubayi, Toriola and Amusa (2013) who found that females were not supported and encouraged to participate in school sports. Thus, this study suggests that parents, peers and other stakeholders such as sport coaches, teachers, and people from the community should play an integral part in supporting females to participate in sport. Interestingly, lack of time was found as the least barrier to sport participation. This finding is surprising and 
unexpected as previous studies (e.g. Robbins, Pender, \& Kazanis, 2003; Saxena, Borzekowski, \& Rickert, 2002) have reported lack of time as a major barrier to sport and physical activity participation. Therefore, it is possible that, the so-called lack of time reported in previous studies may be used as an excuse for physical inactivity. This view is supported by Weinberg and Gould (2011) who stated that: "people often cite time constraints for not exercising, but such constraints are more perceived than real and often reveal a person's priorities".

\section{Limitations and implications for future research}

The results of this study provide baseline information in the current literature on sociocultural constraints to sport participation among female students in rural areas. However, the study has several limitations. Firstly, the sample of the study was too small. It is desirable to collect the data on larger samples of female students in rural areas in order to draw an informative conclusion. Secondly, this research was carried out in one small rural area, therefore the results may not be generalised to all South African rural areas. However, it may be interesting to replicate the study in other rural areas and compare the findings.

\section{Conclusion}

The results of this study indicated that dress code, lack of energy, lack of family support and family commitment were the major barriers to sport participation among high school female students in Hlanganani rural area of Limpopo Province in South Africa. Notwithstanding these constraints, it is recommended that in order to promote sport participation in rural areas, the values, norms, beliefs, attitudes and customs that restrict females from participation in sport and physical activity should be dissented.

\section{References}

Abbasi, I.N. (2014) Socio-cultural barriers to attaining recommended levels of physical activity among females: A review of literature. Quest, 66(4), 448-467.

Allison, K.R., Dwyer, J.J.M. \& Makin, S. (1999). Perceived barriers to physical activity among high school students. Preventive Medicine, 28, 608-615.

Amusa, L.O., Toriola, A.L., Onyewadume, I.U. \& Dhaliwal, H.S. (2008). Perceived barriers to sport and recreation participation in Botswana. African Journal for Physical, Health Education, Recreation and Dance, 14(2), 115-129.

Babbie, E. R. (1990). Survey Research Methods. Belmont, CA: Wadsworth.

Couper, M. P. (2000). Web surveys: A review of issues and approaches. Public Opinion Quarterly, 64, 464-494.

Crawford, D., \& Godbey, G. (1987). Reconceptualising barriers to family leisure. Leisure Sciences, 9, 119-127.

Crawford, D., Jackson, E. \& Godbey, G. (1991). A hierarchical model of leisure constraints. Leisure Sciences, 13, 309-320.

Ewing, M.E. \& Seefeldt, V. (1989). Participation and Attrition Patterns in American Agency-Sponsored and Interscholastic Sports: An Executive Summary. Final Report. North Palm Beach, FL: Sporting Goods Manufacturers Association.

Frantz, J. M. \& Ngambare, R. (2013). Physical activity and health promotion strategies among physiotherapists in Rwanda. African Health Sciences, 13 (1), 17 - 23.

Kim, D., \& Kim S.Y. (1995). QUESEC: An instrument for assessing the service quality of sport centres in Korea. Journal of Sport Management, 6, 208-220.

Kubayi, N.A., Goon, D.T., Coopoo, Y. \& Amusa, L.O. (2013). Physical activity and sedentary behaviour among high school adolescents in Hlanganani rural area, Limpopo province, Souh Africa. African Journal for Physical, Health Education, Recreation and Dance, December (Supplement 1:2), 459-465.

Kubayi, N.A., Toriola, A.L., \& Monyeki, M.A. (2013). Barriers to school sport participation: A survey among secondary school students in Pretoria, South Africa. African Journal for Physical, Health Education, Recreation and Dance, 19(2), 336-344.

Malan, P.E. \& Van Deventer, K.J. (2013). Perceived physical characteristics, personal and social reasons for adolescent sports participation among 15- and 17-year-old boys and girls in the Western Cape Province, South 
Africa. African Journal for Physical, Health Education, Recreation and Dance, 19(4:1), 937-953.

Mchunu, S. \& Le Roux, K. (2010). Non-participation in sport by black learners with special reference to gender, grades, family income and home environment. South African Journal for Research in Sport, Physical Education and Recreation, 32(1), 85-98.

Nunally, J. C. (1978). Psychometric Theory. New York: McGraw Hill.

Ongong'a, J.O. Okwara, M.O. \& Okello, T.M. (2010). Sports and secondary school Education in Kenya. Educational Research, 1(11), 609-617.

Pule, E.R.J., Kubayi, N.A., Toriola, A.L. \& Amusa, L.O. (2013). Sport participation among high school learners in Atteridgeville Township, Pretoria: A survey of disabling and enabling factors. African Journal for Physical, Health Education, Recreation and Dance, December (Suppl.1:2), 466-473.

Robbins, L. B., Pender, N. J., \& Kazanis, A. S. (2003). Barriers to physical activity perceived by adolescent girls. Journal of Midwifery and Women's Health, 48, 206-212.

Sekeran, U. (2003). Research Methods for business: A Skilled building Approach (4 ${ }^{\text {th }}$ Edition). New York: John Willey.

Saxena, R., Borzekowski, D. L. \& Rickert, V. L (2002). Physical activity levels among urban adolescent females. Journal of Paediatric and Adolescent Gynaecology, 15, 279/284.

Van Deventer, J.K (1998). The state of participation in physical activities by high school learners: A survey in some Western Cape schools involving learners, teachers and parents. South African Journal for Research in Sport, Physical Education and Research, 21, 89-102.

Van Hout, R.C.H., Young, M.E.M., Bassett, S.H. \& Hooft, T. (2013). Participation in sport and the perceptions of quality of life of high school learners in the Theewaterskloof Municipality, South Africa. African Journal for Physical, Health Education, Recreation and Dance, 19(3), 612-622.

Walter, C.M. \& Du Randt, R. (2011). Socio-cultural barriers to physical activity among black IsiXhosa speaking professional women in the Nelson Mandela Metropolitan Municipality. South African Journal for Research in Sport, Physical education and Recreation, 33 (2), 143-155.

Weinberg, R. S. \& Gould, D. (2011). Foundation of Sport and Exercise Psychology (5 ${ }^{\text {th }}$ ed.). Champaign, IL: Human Kinetics.

Walseth, K., \& Fasting, K. (2003). Islam's view on physical activity and sport: Egyptian women interpreting Islam. International Review for the Sociology of Sport, 38(1), 45-60. 